\title{
Airport Congestion Pricing and Passenger Types
}

Achim I. Czerny

WHU - Otto Beisheim School of Management achim.czerny@whu.edu
Anming Zhang

Sauder School of Business University of British Columbia anming.zhang@sauder.ubc.ca

WHU - Working Paper

Series in Economics

WP 10/01 


\title{
Airport Congestion Pricing and Passenger Types
}

\author{
Achim I. Czerny \\ WHU - Otto Beisheim School of Management \\ Burgplatz 2, 56179 Vallendar, Germany \\ Phone: +49 261 6509-223, \\ achim.czerny@whu.edu \\ Anming Zhang \\ Sauder School of Business, University of British Columbia \\ 2053 Main Mall, Vancouver, BC, Canada V6T $1 Z 2$ \\ Phone: +1 604 822-8420 \\ anming.zhang@sauder.ubc.ca \\ January 2010, Revised September 2010
}

\begin{abstract}
We consider a public and congested airport served by airlines that may have market power, and two types of travelers with different relative values of time. We find that in the absence of passenger-type-based price discrimination by airlines, it can be useful to increase the airport charge so as to protect passengers with a great relative time value from excessive congestion caused by passengers with a low relative time value. As a result, the socially efficient airport charge can be substantially higher than what we learned from the recent literature on congestion pricing with non-atomistic airlines.
\end{abstract}

JEL Classification: D42, D62, H42, L12, L51, L93, R41, R48.

Keywords: Airports, airlines, passenger types, value of time, congestion, pricing. 
Acknowledgement: We are very grateful to two anonymous referees for their perceptive and very helpful comments. Financial support from the Social Science and Humanities Research Council of Canada (SSHRC) is gratefully acknowledged. 


\section{Introduction}

Air transport has realized impressive growth during the last several decades and is expected to grow at high rates in the future. This development is however not paralleled by a respective increase in airport capacity; airport congestion management is therefore of growing importance. One way to manage congestion is to increase airport charges, thereby reducing the capacity demand, until the socially optimal level of congestion is reached, which we shall call "airport congestion pricing." The optimal charge that achieves this objective is however not easy to identify in the case of airports. We concentrate on three important aspects of air transport business that complicate this identification. First, air transport markets include a vertical structure with airports in the upstream market and airlines in the downstream market. Second, airlines at congested airports usually are not perfectly competitive but oligopolistic. Third, passengers may not be a homogenous group of individuals but differ with regard to their values of time in a situation with traffic delays. Regarding time valuation, Morrison (1987), Morrison and Winston (1989) and Pels et al. (2003), among others, presented empirical evidence that business passengers have a greater value of time than leisure passengers. ${ }^{1}$

Taking the first two aspects into consideration, recent analytical work, including Brueckner (2002), Pels and Verhoef (2004), Zhang and Zhang (2006), Basso and Zhang (2008) and Brueckner and van Dender (2008), finds that monopoly or oligopoly airlines may themselves internalize congestion and as a consequence, the (socially) optimal airport charge should be reduced from the level computed assuming airlines are atomistic (like individual drivers on

\footnotetext{
${ }^{1}$ Furthermore, according to the US Department of Transportation's guidelines of 1997, business passengers' travel time should be valued at 100 percent of the wage, while the leisure passengers' travel time at 70 percent of the wage.
} 
a road). ${ }^{2}$ More specifically, consider a public and congested airport which is served by $n$ symmetric airlines. With the airport choosing charges to maximize welfare (sum of consumer surplus and the airline and airport profits) prior to airlines' Cournot competition, the recent literature finds a negative relationship between the optimal airport charge and airline market concentration or equivalently, market shares $(1 / n)$. There are two reasons for such a relationship. First, airlines partly internalize marginal congestion costs if these are self-imposed, which depends on market shares. This leads to a general rule that implies an inverse relationship between the optimal airport charge and market concentration. Second, as pointed out by Pels and Verhoef (2004) and others, there is a "market power" effect: Since equilibrium airfares increase in market concentration, the airport charge should be small or even negative so as to induce low airfares downstream, thereby correcting for market power at the airline level.

The present paper follows this analytical literature but incorporates the third aspect of air transport business into the analysis. Specifically, we consider two types of travelers (rather than just a single passenger type as is in the literature) one of which has a higher value of time than the other. To focus on the effect of passenger types on the optimal airport charge, we assume away the possibility of price discrimination based on passenger types so airlines charge all passengers a single ticket price. We find that it can be useful to increase the airport charge so as to protect passengers with a great relative time value from excessive congestion caused by passengers with a low relative time value. Furthermore, our results demonstrate that the effect of passenger types can dominate the market-power effect with non-atomistic airlines. Here, the carriers would under-supply the output of high-time-value

\footnotetext{
${ }^{2}$ See Daniel (1995) for earlier work on the internalization idea.
} 
passengers relative to the socially efficient level, owing to a single ticket price being charged. Our analysis also shows that the relationship between the optimal airport charge and the differences in time valuation is not clear-cut, however. This is because passengers with a great time value should not be protected with higher airport charges if their net benefits of flying - that is, their gross benefits net of congestion costs which, for given total traffic volume, increase in passengers' value of time - are small.

We note that the existence of passenger types with different time values can provide an explanation for an empirical situation that seems to be inconsistent with self-internalization. This is of special interest because, in contrast to the theoretical results discussed above, the empirical findings with regard to the relationship between internalization and market concentration are mixed. Brueckner (2002) and Mayer and Sinai (2003) find positive evidence for the internalization of self-imposed congestion costs, whilst Daniel (1995) and Daniel and Harback (2008) reject self-internalization based on their empirical results. Morrison and Winston (2007) conclude, empirically, that the welfare loss would be small if, in the process of choosing the optimal airport charges, airline market shares would be ignored (i.e. carriers were treated as atomistic even though they are non-atomistic). Our results imply that the existence of passenger types with different time values can reduce the welfare loss when the airport charge is not corrected for market shares, which is consistent with Morrison and Winston's conclusion. As such, our results may provide a theoretical explanation for their empirical results.

The paper is organized as follows: Section 2 presents the basic model and investigates equilibrium demands of business and leisure passengers. We turn to airport congestion pricing under the airport-airline vertical structure in Section 3. After examination of the first-best passenger numbers and airfare, 
the section is divided into three subsections. The first subsection analyzes airline behavior for a given airport charge, the second analyzes the optimal airport charge, and the third provides comparative-static results in the business passengers' demand and value of time. Section 4 presents numerical simulations to illustrate the findings of the previous sections, and Section 5 contains concluding remarks.

\section{The Model}

\subsection{Basic set-up}

We start by describing the demand side. Passengers are of two types that are, in what follows, referred to as business and leisure passengers. ${ }^{3}$ Let $q_{B}$ denote the number of business passengers and $q_{L}$ the number of leisure passengers. Setting aside congestion, the (gross) benefits from air travel are $B_{B}\left(q_{B}\right)$ for business passengers and the benefits are $B_{L}\left(q_{L}\right)$ for leisure passengers. The benefit functions are three times continuously differentiable with $B_{x}^{\prime}>0$ and $B_{x}^{\prime \prime}<0$ for $x \in\{B, L\}$.

There is a single public and congested airport. Average delays, which are the same for all passengers, are denoted by $C(q)$ with total passengers $q=q_{B}+q_{L}, C^{\prime}>0$ and $C^{\prime \prime} \geq 0$. Passengers take average delays as given. Denoting the business passengers' value of time by $v_{B}$ and the leisure passengers' by $v_{L}$ with $v_{B} \geq v_{L}(>0)$, the inverse demands of business or leisure passengers can be written as

$$
P_{x}\left(q_{B}, q_{L}\right)=B_{x}^{\prime}\left(q_{x}\right)-v_{x} C(q) .
$$

\footnotetext{
${ }^{3}$ The reference to business/leisure passengers is just for expositional convenience. All we need for the analysis of this paper is the existence of two types of passengers, one of which has a higher time value than the other.
} 
Turning to the supply side, there are $n$ airlines serving the airport and airline services are homogenous. Let $q_{i B}\left(q_{i L}\right.$, respectively) denote the number of business (leisure, respectively) passengers served by airline $i$, with $i=1,2, \ldots, n$, and $q_{x} \equiv \sum_{i=1}^{n} q_{i x}$ for $x \in\{B, L\}$. The airport charges a price $\tau$ per passenger to airlines. ${ }^{4}$ Other marginal airline costs, including the airlines' congestion costs, are constant and normalized to zero. The simplifying assumption on airline costs allows us to concentrate on the effect of the differences in passengers' time valuation. In this context, airline profits are

$$
\Pi_{i}=\sum_{x} q_{i x}\left[P_{x}\left(q_{B}, q_{L}\right)-\tau\right]
$$

and social welfare is

$$
W\left(q_{B}, q_{L}\right)=\sum_{x}\left[\left(B_{x}\left(q_{x}\right)-q_{x} v_{x} C(q)\right]\right.
$$

which is the sum of consumer surplus and the airline and airport profits.

As is common in the literature, the airport-airline vertical structure is modeled as a two-stage game. In the first stage, the airport chooses $\tau$ to maximize welfare, $W$, taking into account airline (equilibrium) responses in stage 2. In the second stage, taking $\tau$ as given airlines choose passenger quantities to maximize $\Pi_{i}$ (i.e. airlines are in Cournot competition). As indicated in the introduction, we abstract away from price discrimination; as a consequence, airlines charge business and leisure passengers a single ticket price denoted by $p$.

\footnotetext{
${ }^{4}$ Public subsidies are usually not available for airports nowadays, and therefore negative values of $\tau$ may not be realistic. Nevertheless, we consider both positive and negative values of $\tau$ to simplify the analysis. This is also consistent with the practice of the literature.
} 


\subsection{Equilibrium passenger demands}

We now derive the demands of business and leisure passengers as a function of the ticket price $p$. Since all passengers are charged a single airfare, the condition $P_{B}=P_{L}=p$ must be satisfied in equilibrium. Substituting $p$ for $P_{x}$ in inverse demands (1) and rearranging gives the equilibrium conditions

$$
p-B_{x}^{\prime}+v_{x} C=0
$$

for $x \in\{B, L\}$. We obtain the (equilibrium) demand functions depending on $p$, denoted $D_{B}(p)$ and $D_{L}(p)$, by simultaneously solving these two equilibrium conditions for $q_{B}$ and $q_{L}$. With $D_{x}(p)$, the total passenger demand is then given by $D_{B}(p)+D_{L}(p)$.

Next, we conduct comparative statics of demand functions $D_{B}$ and $D_{L}$ as well as average congestion delays $C$ with respect to airfare $p$. Totally differentiating equilibrium conditions (4) with respect to $p$ and using Cramer's rule to solve for $d q_{B} / d p$ gives

$$
\begin{aligned}
& D_{B}^{\prime}(p)=\frac{d q_{B}}{d p}=\frac{1}{\Psi} \operatorname{det}\left(\begin{array}{ll}
-\frac{\partial\left(p-B_{B}^{\prime}+v_{B} C\right)}{\partial p} & \frac{\partial\left(p-B_{B}^{\prime}+v_{B} C\right)}{\partial q_{L}} \\
-\frac{\partial\left(p-B_{L}^{\prime}+v_{L} C\right)}{\partial p} & \frac{\partial\left(p-B_{L}^{\prime}+v_{L} C\right)}{\partial q_{L}}
\end{array}\right) \\
& =\frac{1}{\Psi}(\underbrace{B_{L}^{\prime \prime}}_{<0}+\underbrace{\left(v_{B}-v_{L}\right) C^{\prime}}_{\geq 0})
\end{aligned}
$$

where

$$
\begin{gathered}
\Psi \equiv \operatorname{det}\left(\begin{array}{ll}
\frac{\partial\left(p-B_{B}^{\prime}+v_{B} C\right)}{\partial q_{B}} & \frac{\partial\left(p-B_{B}^{\prime}+v_{B} C\right)}{\partial q_{L}} \\
\frac{\partial\left(p-B_{L}^{\prime}+v_{L} C\right)}{\partial q_{B}} & \frac{\partial\left(p-B_{L}^{\prime}+v_{L} C\right)}{\partial q_{L}}
\end{array}\right) \\
=B_{B}^{\prime \prime} B_{L}^{\prime \prime}-\left(v_{L} B_{B}^{\prime \prime}+v_{B} B_{L}^{\prime \prime}\right) C^{\prime}>0 .
\end{gathered}
$$


As indicated, the numerator in (5) consists of two terms with opposite signs and hence its sign is ambiguous. As a consequence, the relationship between the business passenger demand and airfare is also ambiguous. In contrast, the similar procedure for deriving $d q_{L} / d p$ yields a clear-cut result:

$$
D_{L}^{\prime}(p)=\frac{d q_{L}}{d p}=\frac{1}{\Psi}\left(B_{B}^{\prime \prime}-\left(v_{B}-v_{L}\right) C^{\prime}\right)<0 .
$$

Summing (5) and (7) further yields

$$
D_{B}^{\prime}(p)+D_{L}^{\prime}(p)=\frac{d\left(q_{B}+q_{L}\right)}{d p}=\frac{1}{\Psi}\left(B_{L}^{\prime \prime}+B_{B}^{\prime \prime}\right)<0 .
$$

Inequality (8) then implies $d C / d p<0$. These comparative-static results are summarized in Lemma 1:

Lemma 1 The sign of $D_{B}^{\prime}(p)$ is ambiguous but $D_{L}^{\prime}(p)<0, D_{B}^{\prime}(p)+D_{L}^{\prime}(p)<$ 0 and $d C\left(D_{B}(p)+D_{L}(p)\right) / d p<0$.

Lemma 1 shows that while the effect of airfare on the number of leisure (business) passengers is negative (ambiguous), the effect on the number of total passengers is clear-cut and negative. As can be seen from (8), this total effect is dictated by the property of downward-sloping demands with respect to "full prices" (i.e. ticket plus delay costs), rather than the distribution of business/leisure passenger mix. Hence, an increase in $p$ will reduce total passengers and, consequently, congestion delays $C$. As a result of falling delays, the effect of a fare increase on quantities $q_{x}$ is ambiguous in principal. It turns out however that in our setting, the ambiguity exists only for the case of business passengers. For leisure passengers a fare increase will, as can be seen from (7), depress their demand due to both a downward-sloping demand and a shift to business passengers who have a high time value relative 
to leisure passengers. On the other hand, the reduction in delays is valued more by business passengers which, holding the fare unchanged, stimulates their demand. The net effect of the fare rise for the business-passenger demand will, as seen from (5), depend on which effect-the downward-sloping demand vs. the demand stimulation from reduced congestion-dominates. These comparative-static results are intuitive because of the great value of time of business passengers relative to leisure passengers.

\section{Effect of Passenger Types on Optimal Air- port Charges}

Before investigating the optimal airport charges under the vertical structure, we discuss the first-best ("welfare optimal") passenger numbers and airfare. The first-best passenger numbers, denoted $\left(q_{B}^{*}, q_{L}^{*}\right)$, are determined by the first-order conditions $\partial W / \partial q_{x}=0$, or using (3) by

$$
B_{x}^{\prime}-v_{x} C(q)-\left(q_{B}^{*} v_{B}+q_{L}^{*} v_{L}\right) C^{\prime}=0
$$

for $x \in\{B, L\}$. Further, substituting $D_{x}(p)$ for $q_{x}$ in (3) gives the welfare as a function of airfare $p, W\left(D_{B}(p), D_{L}(p)\right)$. The welfare-optimal airfare is determined by the following first-order condition:

$$
\frac{d W}{d p}=\sum_{x}\left[B_{x}^{\prime}-v_{x} C-\left(D_{B} v_{B}+D_{L} v_{L}\right) C^{\prime}\right] D_{x}^{\prime}=0 .
$$


Observe that this condition includes the two first-order conditions in (9), which are multiplied by $D_{x}^{\prime}$. Using the equilibrium demands with regard to $p$, condition (10) can be rewritten as

$$
\left[p^{*}-\left(D_{B}\left(p^{*}\right) v_{B}+D_{L}\left(p^{*}\right) v_{L}\right) C^{\prime}\right] \cdot\left(D_{B}^{\prime}+D_{L}^{\prime}\right)=0
$$

Since $D_{B}^{\prime}+D_{L}^{\prime}<0$ by Lemma 1 , the first-best airfare then reduces to

$$
p^{*}=\left(D_{B}\left(p^{*}\right) v_{B}+D_{L}\left(p^{*}\right) v_{L}\right) C^{\prime}
$$

The first-best airfare in (12) has a clear interpretation. Before we turn to this interpretation, note that the total congestion costs are given by $\left(v_{B} q_{B}+v_{L} q_{L}\right) C(q)$ and that the marginal congestion costs depend on the passenger type with

$$
\frac{\partial}{\partial q_{x}}\left(v_{B} q_{B}+v_{L} q_{L}\right) C(q)=v_{x} C+\left(v_{B} q_{B}+v_{L} q_{L}\right) C^{\prime}
$$

Observe that the first term (and only the first term) on the right-hand side (RHS) is deducted from the marginal passenger benefits to come up with the inverse passenger demands in (1). This part is therefore internalized by passengers, while the second term on the RHS of (13) is not. For this reason, we call this second part the external part of the marginal congestion costs. Then, $p^{*}$ in (12) exactly equals the external part of the marginal congestion costs at the welfare optimum. Notice that this induces the first-best passenger numbers because $p^{*}=P_{B}\left(D_{B}\left(p^{*}\right), D_{L}\left(p^{*}\right)\right)=P_{L}\left(D_{B}\left(p^{*}\right), D_{L}\left(p^{*}\right)\right)$ satisfies the first-order conditions $(9)$.

The airport does not directly control airfares but only controls the airport charge. This is because airfares are determined by airlines, which take the 
airport charge as given. In what follows, we examine the welfare-optimal airport charge in our two-stage game by backward induction.

\subsection{Airline behavior}

In the second stage each airline chooses quantity $q_{i}$ to maximize its profit, so we first specify airline profits in terms of quantity. For the total airline supply it holds $\sum_{x} \sum_{i} q_{i x}=q$. Substituting the sum by the total equilibrium demand $D_{B}(p)+D_{L}(p)$ and solving for $p$ gives the equilibrium airfare, which depends on the total number of passengers and is denoted by $P(q)$. After substituting $P(q)$ for $P_{x}$ in (1), we can rewrite airline profits (2) as

$$
\Pi_{i}=q_{i}[P(q)-\tau]
$$

with $q_{i}=q_{i B}+q_{i L}$. Expression (14) gives a carrier's profit in terms of quantities $q_{1}, q_{2}, \ldots, q_{n}$.

The Cournot-Nash equilibrium is determined by the first-order conditions

$$
q_{i} P^{\prime}+P-\tau=0 \text {. }
$$

for $i=1,2, \ldots, n$. While the airport charge, $\tau$, represents the marginal cost of passengers to airlines, the first two terms in (15) give the marginal revenue. Assume declining marginal revenue for the entire range of interest, which ensures the second-order conditions for profit maximization and forms part of the regularity conditions for the existence and uniqueness of the CournotNash equilibrium. Let $q_{i}^{N}(\tau)$ denote the Cournot-Nash equilibrium, and so the total equilibrium quantity is $q^{N}(\tau)=q_{1}^{N}(\tau)+\ldots+q_{n}^{N}(\tau)$, which depends on $\tau$. This in turn yields the equilibrium airfare $P\left(q^{N}(\tau)\right)$, number of business passengers $D_{B}\left(P\left(q^{N}(\tau)\right)\right.$ and number of leisure passengers $D_{L}\left(P\left(q^{N}(\tau)\right)\right.$, all 
of which depend on airport charge $\tau$. The effects of $\tau$ on these variables are given below:

Lemma 2 At the Cournot-Nash equilibrium, $d q^{N}(\tau) / d \tau<0, d P / d \tau>0$ and $d D_{L} / d \tau<0$, but the sign of $d D_{B} / d \tau$ is ambiguous.

Lemma 2 indicates a positive relationship between equilibrium airfare $P\left(q^{N}(\tau)\right)$ and airport charge $\tau$. This can be seen as follows: To satisfy the first-order condition (15), $q_{i}$ must be reduced in response to an increase of $\tau$ given the declining marginal revenue. Then $d q^{N} / d \tau<0$ follows immediately, which further implies $d P / d \tau>0$ by Lemma 1 (which shows a negative relationship between total passengers $D_{B}+D_{L}$ and $p$ ). The other relationships indicated in Lemma 2 follow from the $d P / d \tau>0$ result together with the results obtained in Lemma 1.

\subsection{The optimal airport charge}

Back to the first stage of the game, the public airport chooses $\tau$ to maximize social welfare taking airline behavior into account. Specifically, substituting $D_{x}\left(P\left(q^{N}(\tau)\right)\right.$ for $q_{x}$ in $(3)$ gives welfare depending on $\tau, W\left(D_{B}\left(P\left(q^{N}(\tau)\right)\right), D_{L}\left(P\left(q^{N}(\tau)\right)\right)\right)$. The resulting welfare-optimal charge is characterized by the first-order condition,

$$
\frac{d W}{d \tau}=\frac{d W}{d p} \cdot \frac{d P}{d \tau}=0
$$

This condition is multiplication of two terms: i) the derivative of welfare with respect to the airfare, which has been given in (10) previously (i.e. the firstorder condition for the optimal airfare $\left.p^{*}\right)$; and ii) the derivative of airfare $P$ with respect to $\tau$. Since $d P / d \tau>0$ by Lemma 2, the first-order condition (16) is satisfied if and only if the first-order condition for the optimal airfare, (10), is satisfied. This gives rise to: 
Proposition 1 The welfare-optimal airport charge, $\tau^{*}$, leads to the first-best airfare $p^{*}$ and passenger numbers $\left(q_{B}^{*}, q_{L}^{*}\right)$.

We now examine the nature of airport congestion charges. Since $\tau^{*}$ leads to the welfare-optimal outcome (Proposition 1) and the airline market is symmetric, the optimal airport charge can be rewritten as

$$
\tau^{*}=p^{*}+q_{i}^{N} P^{\prime}=p^{*}+\frac{1}{n} q^{*} P^{\prime}
$$

where $1 / n$ is the airlines' market shares. We further manipulate the airport charge in (17) so as to obtain a more transparent picture about the effect of passenger types. Letting $\varepsilon$ denote the (positive) elasticity of total demand, $D_{B}+D_{L}$, with respect to $p$ - that is, $\varepsilon \equiv-\left(D_{B}^{\prime}+D_{L}^{\prime}\right) \cdot p /\left(D_{B}+D_{L}\right)$-and rearranging (17) gives rise to:

$$
\tau^{*}=p^{*}\left(1-\frac{1}{n} \frac{1}{\varepsilon^{*}}\right)
$$

The optimal airport charge in (18) exhibits two properties. First, it is inversely related to airline market shares, $1 / n$ : when $n \rightarrow \infty$, the optimal airport charge is equal to the external part of the marginal congestion costs or, respectively, to the welfare-optimal airfare $p^{*}$. So, $p^{*}$ equals the optimal airport charge in an atomistic airline market. In the remainder of the paper, we therefore refer to $p^{*}$ as the optimal airfare or, respectively, the atomistic airport charge. With this second interpretation, $p^{*}$ will serve us as one benchmark for the airport charge in a context where two types of travelers with different values of time exist. Second, $\tau^{*}$ is inversely related to the inverse demand elasticity of passengers, $1 / \varepsilon^{*}{ }^{5}$

\footnotetext{
${ }^{5}$ This reproduces the results obtained by Zhang and Zhang (2006) who elaborate on the single-type passenger model. Also see, for example, Daniel (1995), Brueckner (2002),
} 
To identify the effect of passenger types on $\tau^{*}$, assume, for a moment, that $v_{B}=v_{L} \equiv v_{s}$ and $B_{B}=B_{L} \equiv B_{s}$ ( $s$ for "single" type). This scenario is the same as a situation where only a single passenger type exists (all passengers are of type $s$ ) and implies

$$
\varepsilon_{s}^{*}=-\left(D_{B}^{\prime}+D_{L}^{\prime}\right) \frac{p^{*}}{q^{*}}=\frac{v_{s} C^{\prime}}{v_{s} C^{\prime}-\frac{B_{s}^{\prime \prime}}{2}},
$$

where the first equality follows from the definition of $\varepsilon$ and the second equality follows from the use of (8), (6), (12), $v_{B}=v_{L} \equiv v_{s}$ and $B_{B}=B_{L} \equiv B_{s}$. Observe that the RHS of (19) is greater than 0 and less than 1 , but that the limit of $\varepsilon_{s}$ is equal to 1 for $B_{s}^{\prime \prime} \rightarrow 0$. Note that $B_{s}^{\prime \prime} \rightarrow 0$ implies that airlines have no market power in the sense that the "full price", $P+v_{s} C$, is fully determined by marginal benefits. Then, in this single-type situation, $\tau_{s}^{*}$ can be obtained by substituting $\varepsilon_{s}^{*}$ for $\varepsilon^{*}$ in (18).

There is a unique constellation where airline charges reproduce $p^{*}$ though $\tau=0$, that is, no regulatory intervention is required in this constellation because airlines choose prices just right from the social viewpoint. This is when $n=1$ and $\varepsilon_{s}=1$ (i.e. $B_{s}^{\prime \prime} \rightarrow 0$ ), which represents a situation with a monopoly airline that possesses no market power. No intervention is due in this situation because, first, all the congestion costs will be internalized by the monopolist and there would be no room for congestion tolls to be levied. Second, the airport charge need not correct for market power by subsidizing airline operations because passenger demand is perfectly elastic in the full price. ${ }^{6}$ In contrast, if $\varepsilon_{s}=1$ and $n>1$, full internalization cannot always be

Pels and Verhoef (2004), Basso and Zhang (2008) and Brueckner and van Dender (2008) who obtained similar results with different model settings.

${ }^{6}$ While the elasticities of demand with respect to the full price is generally finite in reality, researchers (for example, Brueckner and van Dender, 2008; Brueckner, 2009; and 
achieved and therefore the optimal airport charge becomes positive, that is $\tau_{s}^{*}=p^{*}[1-(1 / n)]>0$.

Furthermore, if $(0<) \varepsilon_{s}<1$ and $n=1$, congestion costs are perfectly internalized but the airline market power exists. As a result, the optimal airport charge becomes negative, that is, $\tau_{s}^{*}=p^{*}\left[1-\left(1 / \varepsilon_{s}^{*}\right)\right]<0$. Thus, for the general single-passenger type case (i.e. with $\varepsilon_{s}<1$ and $n \geq 1$ ) we have $\tau_{s}^{*}<p^{*}[1-(1 / n)]$ or equivalently,

$$
\frac{\tau_{s}^{*}}{p^{*}}<1-\frac{1}{n}
$$

and consequently $\tau_{s}^{*}<p^{*}$. The upper limit for $\tau_{s}^{*} / p^{*}$, given by the RHS of (20), will serve us as a second benchmark for the two passenger-types case.

Turning to the case with two passenger types where $v_{B}>v_{L}$, the optimal airport charge is determined by (17). In contrast to the single passenger-type case where $\varepsilon_{s}^{*}<1$, with two passenger types parameter constellations can occur that imply $\varepsilon^{*}>1$. To see this, $\varepsilon^{*}>1$ is, by using the definition of $\varepsilon$, (8), (6) and (12), equivalent to

$$
\varepsilon^{*}=-\frac{B_{L}^{\prime \prime}+B_{B}^{\prime \prime}}{B_{B}^{\prime \prime} B_{L}^{\prime \prime}-\left(v_{L} B_{B}^{\prime \prime}+v_{B} B_{L}^{\prime \prime}\right) C^{\prime}} \frac{\left(v_{B} q_{B}^{*}+v_{L} q_{L}^{*}\right) C^{\prime}}{q_{B}^{*}+q_{L}^{*}}>1 .
$$

Manipulation of inequality (21) then yields

$$
\left(\frac{q_{B}^{*}}{q_{B}^{*}+q_{L}^{*}}-\frac{B_{L}^{\prime \prime}}{B_{B}^{\prime \prime}+B_{L}^{\prime \prime}}\right)\left(v_{B}-v_{L}\right)>-\frac{B_{B}^{\prime \prime} B_{L}^{\prime \prime}}{\left(B_{B}^{\prime \prime}+B_{L}^{\prime \prime}\right) C^{\prime}}
$$

Note that the RHS of inequality (22) is strictly positive. As a consequence, when $v_{B}=v_{L}$, the inequality won't hold and hence $\varepsilon^{*}=\varepsilon_{s}^{*} \leq 1$ as indicated above. On the other hand, when $v_{B}>v_{L}$, constellations exist such that Basso and Zhang, 2010) have considered models with perfectly elastic demands so as to concentrate their analysis on pure congestion pricing. 
inequality (22) holds. Consider, for example, the specific functional forms used in Section 4 below. If we let $a>1, b=1 / 5$ and $v_{B}$ is large enough relative to $v_{L}(=1)$, then $(22)$ can be shown to hold (see further illustration in Section 4$)$. As a result, we have $\varepsilon^{*}>1$ and hence by $(18), \tau^{*}>p^{*}[1-(1 / n)]$, which is in contrast to the result of the single passenger type given in (20). With different passenger types it can thus be useful to charge oligopolistic airlines a price that exceeds the level of the external part of the marginal congestion costs. This is in sharp contrast to the notion of Pels and Verhoef (2004) who argued that the welfare-optimal airport charge is always lower than the external part of the marginal congestion costs when airline markets are oligopolistic. The "technical" reason is that greater values of $v_{B}$ shift the passenger demand downwards, which increases the price elasticity of business passenger demand and therefore the elasticity of total passenger demand as well. A more intuitive interpretation, which follows implicitly from our analysis, is however that greater airfares can be required to protect business passengers (with a great relative time value) from congestion caused by leisure passengers who are less sensitive with regard to congestion than business passengers. But, $\tau^{*}$ never reaches the level of the atomistic airport charge, since $\tau^{*}<p^{*}$.

Summarizing the above discussion leads to:

Proposition 2 In a context of two types of travelers with different relative values of time, it can be useful to increase the airport charge so as to protect passengers with a great relative time value from excessive congestion caused by passengers with a low relative time value. As a result, the socially efficient airport charge can be higher than what would prevail if passengers were treated as a single type but it will never reach the level of the atomistic airport charge. 


\subsection{Comparative-static results}

We are also interested in the relationship between various optimal variables (for example, the optimal numbers of business and leisure passengers, optimal airfares, full prices, optimal airport charges) and the business passengers' benefits or their value of time. For this reason, we introduce parameter $a(>0)$ with

$$
\frac{\partial B_{B}^{\prime}\left(q_{B}\right)}{\partial a} \geq 0
$$

for all $q_{B}>0$, where $a$ establishes a positive relationship with the inverse business passenger demand. We obtain the following comparative-static results:

Proposition 3 In a context with business passengers having a greater value of time than leisure passengers, the following clear-cut relationships exist:

$$
\frac{d q_{B}^{*}}{d a}>0, \frac{d q_{L}^{*}}{d a}<0, \frac{d q_{B}^{*}}{d v_{B}}<0 \text { and } \frac{d q_{L}^{*}}{d v_{B}}>0
$$

In contrast, the relationships

$$
\frac{d\left(q_{B}^{*}+q_{L}^{*}\right)}{d z}, \frac{d p^{*}}{d z} \text { and } \frac{d \tau^{*}}{d z}
$$

are all ambiguous in sign for $z \in\left\{a, v_{B}\right\}$.

The proof is relatively straightforward but tedious, and is given in Appendix A. The comparative-static results with regard to $a$ in (24) show that a positive relationship between $a$ and the optimal number of business passengers exists, while this relationship is negative for leisure passengers. On the other hand, the comparative static results with regard to the business passengers' value of time, $v_{B}$, in (24) show that a negative relationship between 
$v_{B}$ and the number of business passengers, $q_{B}^{*}$, exists, while this relationship is positive in the case of leisure passengers.

The comparative static results in (25) are ambiguous; hence, there is no clear-cut relationship between $a$ or $v_{B}$ and the total number of passengers, $q_{B}^{*}+q_{L}^{*}$, the optimal airfare, $p^{*}$, and the optimal airport charge, $\tau^{*}$. Take the relationship between $\tau^{*}$ and $v_{B}$ as an example. For low values of $v_{B}$ (but still greater than $v_{L}$ ) an increase of $\tau$ can be useful in protecting business passengers from excessive congestion. The picture changes for great values of $v_{B}$. In that situation, it may not be useful anymore to protect business passengers from congestion because their benefits from flying net of congestion costs are too small, which altogether provides an economic intuition for the ambiguous relationships in (25). In the next section, we present numerical simulations to illustrate the finding of the previous sections.

\section{Numerical Simulations}

In this section, we first present a specific model on which our numerical simulations will be based. Second, we present numerical results.

Assume that passenger benefits are

$$
B_{B}\left(q_{B}\right)=a q_{B}-\frac{q_{B}^{2}}{2} \text { and } B_{L}\left(q_{L}\right)=q_{L}-b \frac{q_{L}^{2}}{2}
$$

with

$$
a \in\left[\frac{1+v_{B}}{2+b}, \frac{1+2 v_{B}}{1+v_{B}}\right]
$$

and $b \geq 0$. The lower limit for $a$ ensures that the number of business passengers is non-negative, while the upper limit ensures that the number of leisure 
passengers is non-negative. For the leisure passengers' value of time it holds $v_{L}=1$ and the business passengers' value of time is

$$
v_{B} \in\left[a(2+b)-1, \min \left\{a(2+b)-1,1+b+\sqrt{2+3 b+b^{2}}\right\}\right] .
$$

The lower limit for $v_{B}$ ensures that the number of leisure passengers is nonnegative. The upper limit ensures that the number of business passengers is non-negative (this is the case if $\min \{\cdot\}$ equals the first expression) or that the second-order condition for the welfare optimal passenger numbers are satisfied (this is the case if $\min \{\cdot\}$ equals the second expression). Average delays are linear in the passenger number, that is

$$
C\left(q_{B}, q_{L}\right)=q_{B}+q_{L},
$$

while average congestion costs can be non-linear in reality. Furthermore, Equations (21) and (22) show that the shape of average delays determines the elasticity of total demand with respect to $p, \varepsilon$, and the critical value of $v_{B}$ that has to be reached such that $\varepsilon^{*}>1$. However, the main numerical results presented in this section should remain robust against changes in the shape of average delays.

Benefits in (26) and average delays in (29) imply first-best passenger numbers

$$
q_{B}^{*}=\frac{2 a+a b-\left(v_{B}+1\right)}{2 b v_{B}+b-v_{B}^{2}+2 v_{B}+1} \text { and } q_{L}^{*}=\frac{1+2 v_{B}-a\left(v_{B}+1\right)}{2 b v_{B}+b-v_{B}^{2}+2 v_{B}+1} \text {. }
$$

and the airfare

$$
p^{*}=\frac{a b v_{B}+a v_{B}-a-v_{B}^{2}+v_{B}+1}{2 b v_{B}+b-v_{B}^{2}+2 v_{B}+1} .
$$


The optimal airport charge $\tau^{*}$ is

$$
\tau^{*}=1+\frac{1}{n}\left(\frac{(n+1)\left((a b+a-2 b-1) v_{B}-a-b\right)}{2(b+1) v_{B}+b-v_{B}^{2}+1}-\frac{b(a-1)}{b+1}\right)
$$

and depends on $n$.

As discussed earlier, the results obtained in the recent literature indicate that the ratio of the optimal airport charge in an oligopolistic airline market with the optimal one in an atomistic airline market should be inversely related with an airline's market share, that is a negative relationship between an airline's market share and the optimal airport charge should exist. Moreover, Pels and Verhoef (2004) pointed out that it can be useful to further decrease the degree of internalization so as to correct for market power and price mark-ups in an oligopolistic airline market. We use Figure 1 to illustrate that the existence of passengers with different values of time can change the picture and move the optimal airport charges in an oligopolistic airline market scenario considerably closer to the level that would hold under atomistic market conditions. Note that this result can provide some theoretical support for the empirical findings of Morrison and Winston (2007), who conclude that the welfare loss would be small if, in the process of choosing the airport charge, carriers were treated as atomistic even though they are oligopolistic. ${ }^{7}$

Figure 1 depicts the ratios of the optimal airport charge and the atomistic airport charge, $\tau^{*} / p^{*}$. The solid horizontal line equals $2 / 3$, which equals the total market share of any two of the three firms assumed in the example. Parameters are $a=15 / 10$ (the solid line) or $a=16 / 10$ (the dashed line), $b=1 / 5$ and $n=3$. Functions are shown for the relevant ranges of $v_{B}$,

\footnotetext{
${ }^{7}$ Another explanation is the existence of a dominant airline that competes in a Stackelberg fashion with a large number of fringe carriers (see, for example, Daniel, 1995; and Brueckner and van Dender, 2008). The Stackelberg setting seems however rather restrictive compared to the assumption of passenger types with different values of time.
} 


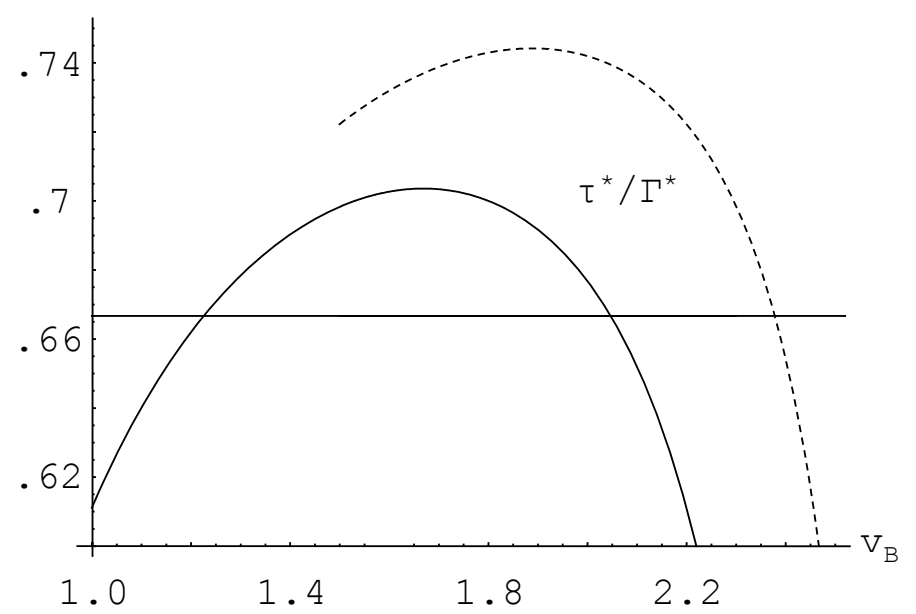

Figure 1: The ratios of the optimal airport charge and the atomistic airport charge, $\tau^{*} / p^{*}$. The solid horizontal line equals $2 / 3$, which equals the total market share of 2 firms. Parameters: $a=15 / 10$ (solid line) or $a=16 / 10$ (dashed line), $b=1 / 5$ and $n=3$. Functions are shown for the relevant ranges of $v_{B}$.

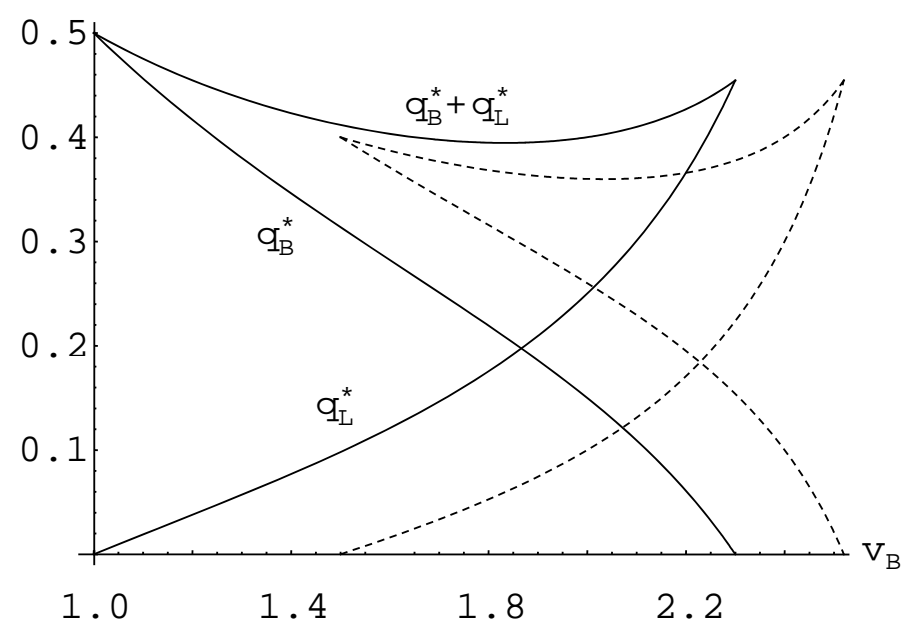

Figure 2: The optimal passenger numbers, $q_{B}^{*}$ and $q_{L}^{*}$, and the optimal total passenger number, $q_{B}^{*}+q_{L}^{*}$. Parameters: $a=15 / 10$ (solid line) or $a=16 / 10$ (dashed line), $b=1 / 5$ and $n=3$. Functions are shown for the relevant ranges of $v_{B}$. 
which are determined by (28). We know from the previous literature that, with a single group of passengers, the ratio of the optimal airport charge, $\tau^{*}$, and the one in an atomistic setting, $p^{*}$, should be less than the total market share of $n-1$ airlines, which is equal to $2 / 3$ for the current instance. Figure 1 reproduces this result because $\tau^{*} / p^{*}<2 / 3$ for $v_{B}=1$ (recall that $v_{L}=1$ ). However, the figure also shows that when $v_{B}$ increases, the value of $\tau^{*} / p^{*}$ may also increase and exceed the level of $2 / 3$ substantially. This effect is even stronger for a larger value of $a$ (compare the solid line with $a=15 / 10$ with the dashed line with $a=16 / 10)$.

Figure 2 depicts the optimal passengers numbers, $q_{B}^{*}$ and $q_{L}^{*}$, and the optimal total passenger number, $q_{B}^{*}+q_{L}^{*}$, for the same parameter constellations as the ones that we used to plot Figure 1. It shows that the optimal number of business passengers is decreasing in $v_{B}$ while the optimal number of leisure passengers is increasing in $v_{B}$. Observe that the relationship between the total number of passengers and $v_{B}$ is ambiguous. Altogether, these graphs illustrate some of our findings in Proposition 3.

\section{Concluding Remarks}

Our main objective in writing this paper is to analytically explore airport congestion pricing with two types of travelers, with one type (business passengers) exhibiting a higher time value than the other (leisure passengers). We have considered a model with a public and congested airport together with an oligopolistic airline market. Airlines served two types of passengers, which included business passengers with a great relative value of time and leisure passengers with a low relative value of time. All passengers are charged with a single ticket price. We demonstrated that the existence of 
passenger types with different values of time can have a substantial impact on the choice of airport charges. In this situation, it can be useful to increase airport charges and thus airfares to protect business passengers from excessive congestion caused by leisure passengers who are less sensitive to congestion. As a consequence, the welfare-optimal airport charge can exceed the level of the external part of the marginal congestion costs.

There are two critical elements in our model. One is that airlines charge all passengers with a single ticket price. In practice, airlines price discriminate between business and leisure passengers. One way is to increase airfares when departure times get close. This can be an effective way to charge business passengers with a higher airfare than leisure passengers because leisure passengers often book their flights far in advance, which is not necessarily true for business passengers. ${ }^{8}$ In this paper, we have abstracted away from airline price discrimination in order to concentrate on the differences in passenger types with regard to their value of time and the consequences for airport congestion pricing. This allows us to establish a benchmark case and is consistent with the uniform pricing case in the literature. The introduction of airline price discrimination is certainly important (and is consistent with the existing airline practice) and represents a natural extension of the analysis presented here. Allowing price discrimination will add significant complexity to the analysis, while basic insights of the paper should remain robust.

Another critical element is the consideration of only two values of time. In practice, many more passenger types with different values of time may exist. It would therefore be useful to analyze a model that is more general with regard to the distribution of time values. Overall, the research provided

\footnotetext{
${ }^{8}$ Hazledine (2006) argued that airline price discrimination would be based on an inverse relationship between passengers' benefits, and the time left before departure time.
} 
in this paper captures the effect of passenger types on airport congestion pricing in a simple model with two types, which has not yet been explored by other economists. However, future research is required to obtain a more complete picture of the role of passenger types.

\section{A Proof of Proposition 3}

To determine the signs of $d q_{x}^{*} / d z, d p^{*} / d z$, and $d \tau^{*} / d z$ with $z \in\left\{a, v_{B}\right\}$, the first step is to determine the second partial derivatives of welfare in function (3), which give

$$
\frac{\partial^{2} W}{\partial q_{x}^{2}}=B_{x}^{\prime \prime}-2 v_{x} C^{\prime}-\left(q_{B} v_{B}+q_{L} v_{L}\right) C^{\prime \prime}<0
$$

and

$$
\frac{\partial^{2} W}{\partial q_{B} \partial q_{L}}=-v_{B} C^{\prime}-v_{L} C^{\prime}-\left(q_{B} v_{B}+q_{L} v_{L}\right) C^{\prime \prime}<0
$$

We also need the second partial derivatives of welfare in (3) with respect to $q_{x}$ and $z$, which give

$$
\frac{\partial^{2} W}{\partial q_{B} \partial a}=\frac{\partial B_{B}^{\prime}}{\partial a}>0, \frac{\partial^{2} W}{\partial q_{L} \partial a}=0, \frac{\partial^{2} W}{\partial q_{B} \partial v_{B}}=-C-q_{B} v_{B} C^{\prime}<0
$$

and

$$
\frac{\partial^{2} W}{\partial q_{L} \partial v_{B}}=0 .
$$

Furthermore, we assume that the Hessian of the welfare function, denoted by $\Omega$, is strictly positive to ensure the existence of solutions for welfare maximization. 
Using Cramer's rule to solve for $d q_{B}^{*} / d a$ yields

$$
\begin{gathered}
\frac{d q_{B}^{*}}{d a}=\frac{1}{\Omega} \operatorname{det}\left(\begin{array}{cc}
-\frac{\partial^{2} W}{\partial q_{B} \partial a} & \frac{\partial^{2} W}{\partial q_{B} \partial q_{L}} \\
-\frac{\partial^{2} W}{\partial q_{L} \partial a} & \frac{\partial^{2} W}{\partial q_{L}^{2}}
\end{array}\right)= \\
\frac{1}{\Omega}\left(-\frac{\partial B_{B}^{\prime}}{\partial a}\left[B_{L}^{\prime \prime}-2 v_{L} C^{\prime}-\left(q_{B} v_{B}+q_{L} v_{L}\right) C^{\prime \prime}\right]\right)>0,
\end{gathered}
$$

and solving for $d q_{L}^{*} / d a$ yields

$$
\frac{d q_{L}^{*}}{d a}=\frac{1}{\Omega}\left(-\frac{\partial B_{B}^{\prime}}{\partial a}\left[\left(v_{B}+v_{L}\right) C^{\prime}+\left(q_{B} v_{B}+q_{L} v_{L}\right) C^{\prime \prime}\right]\right)<0 .
$$

Summing (37) and (38) yields

$$
\frac{d\left(q_{B}^{*}+q_{L}^{*}\right)}{d a}=\frac{1}{\Omega}\left(-\frac{\partial B_{B}^{\prime}}{\partial a}\right)\left(B_{L}^{\prime \prime}+\left(v_{B}-v_{L}\right) C^{\prime}\right)
$$

Since $v_{B} \geq v_{L},(39)$ is ambiguous in sign.

Solving for $d q_{B}^{*} / d v_{B}$ yields

$$
\frac{d q_{B}^{*}}{d v_{B}}=\left(C+q_{B} C^{\prime}\right)\left[B_{L}^{\prime \prime}-2 v_{L} C^{\prime}-\left(q_{B} v_{B}+q_{L} v_{L}\right) C^{\prime \prime}\right]<0,
$$

and solving for $d q_{L}^{*} / v_{B}$ yields

$$
\frac{d q_{L}^{*}}{d v_{B}}=-\left[-\left(v_{B}+v_{L}\right) C^{\prime}-\left(q_{B} v_{B}+q_{L} v_{L}\right) C^{\prime \prime}\right]\left(C+q_{B} C^{\prime}\right)>0
$$

Furthermore, summing (40) and (41) yields

$$
\frac{d\left(q_{B}^{*}+q_{L}^{*}\right)}{d v_{B}}=\frac{1}{\Omega}\left(B_{L}^{\prime \prime}+\left(v_{B}-v_{L}\right) C^{\prime}\right)\left(C+q_{B} C^{\prime}\right),
$$

which is ambiguous in sign. 
We turn to airfares and airport charges. For the optimal airfare $p^{*}$ in (12), it holds

$$
\frac{d p^{*}}{d a}=\left(\frac{d q_{B}^{*}}{d a} v_{B}+\frac{d q_{L}^{*}}{d a} v_{L}\right) C^{\prime \prime} \cdot \frac{d\left(q_{B}^{*}+q_{L}^{*}\right)}{d a}
$$

and

$$
\frac{d p^{*}}{d v_{B}}=\left(\frac{d q_{B}^{*}}{d v_{B}} v_{B}+q_{B}^{*}+\frac{d q_{L}^{*}}{d v_{B}} v_{L}\right) C^{\prime \prime} \cdot \frac{d\left(q_{B}^{*}+q_{L}^{*}\right)}{d v_{B}} .
$$

Both relationships in (43) and (44) are ambiguous because the signs of $d\left(q_{B}^{*}+\right.$ $\left.q_{L}^{*}\right) / d z$ are ambiguous for all $z \in\left\{a, v_{B}\right\}$. Since the optimal airport charge $\tau^{*}$ in (17) depends on $p^{*}$, the sign of $d \tau^{*} / d z$ is also ambiguous for all $z \in\left\{a, v_{B}\right\}$.

\section{References}

Basso, L. and Zhang, A. (2008). Sequential peak-load pricing in a vertical setting: The case of airports and airlines. Canadian Journal of Economics, 41:1087-1119.

Basso, L. and Zhang, A. (2010). Pricing vs. slot policies when airport profits matter, Transportation Research, Part B, 44(3):381-391.

Brueckner, J. K. (2002). Airport congestion when carriers have market power. American Economic Review, 92(5):1357-1375.

Brueckner, J. K. (2009). Price vs. quantity based approaches to airport congestion management. Journal of Public Economics, 93(5-6):681690 .

Brueckner, J. K. and van Dender, K. (2008). Atomistic congestion tolls at concentrated airports? Seeking a unified view in the internalization debate. Journal of Urban Economics, 64(2):288-295. 
Daniel, J. I. (1995). Congestion pricing and capacity of large hub airports: A bottleneck model with stochastic queues. Econometrica, 63(2):327370 .

Daniel, J. I. and Harback, K. T. (2008). (When) Do hub airlines internalize their self-imposed congestion delays? Journal of Urban Economics, 63(2):583-612.

Hazledine, T. (2006). Price discrimination in Cournot-Nash oligopoly. Economics Letters, 93(3):413-420.

Mayer, C. and Sinai, T. (2003). Network effects, congestion externalities, and air traffic delays: Or why all delays are not evil. American Economic Review, 93(4):1194-1215.

Morrison, S. A. (1987). The equity and efficiency of runway pricing. Journal of Public Economics, 34(1):45-60.

Morrison, S. A. and Winston, C. (1989). Enhancing the performance of the deregulated air transportation system. Brookings Papers on Economic Activity: Microeconomics, 61-112.

Morrison, S. A. and Winston, C. (2007). Another look at airport congestion pricing. American Economic Review, 97(5):1970-1977.

Pels, E., Nijkamp, P., and Rietveld, P. (2003). Access to and competition between airports: A case study for the San Francisco Bay area. Transportation Research Part A: Policy and Practice, 37(1):71-83.

Pels, E. and Verhoef, E. T. (2004). The economics of airport congestion pricing. Journal of Urban Economics, 55(2):257-277.

US Department of Transportation (1997). The Value of Saving Travel Time: Departmental Guidance for Conducting Economic Evaluations. 
Zhang, A. and Zhang, Y. (2006). Airport capacity and congestion when carriers have market power. Journal of Urban Economics, 60(2):229247. 